\title{
Formic Acid Oxidation on Bi-modified Pt Nanoparticles of Various Sizes
}

\author{
Changhoon Jung, ${ }^{\dagger}$ Ting Zhang, ${ }^{\dagger}$ Byung-Jun Kim, ${ }^{\dagger}$ Jandee Kim, ${ }^{\dagger}$ Choong Kyun Rhee, ${ }^{\dagger}, * *$ and Tae-Hoon Lim ${ }^{\S}$ \\ ${ }^{\dagger}$ Department of Chemistry, Chungnam National University, Daejeon 305-704, Korea \\ ${ }^{\star}$ Graduate School of Analytical Science and Technology, Chungnam National University, Daejeon 305-704, Korea \\ *E-mail: ckrhee@cnu.ac.kr \\ ${ }^{\S}$ Center for Fuel Cell Research, Korea Institute of Science and Technology, Seoul 136-791, Korea \\ Received March 17, 2010, Accepted April 12, 2010
}

\begin{abstract}
This work presents oxidation of formic acid on Bi-modified Pt nanoparticles of various sizes. The sizes of the studied Pt nanoparticles range from 1.5 to 5.6 nm (detailed in Rhee, C. K.; Kim, B.-J.; Ham, C.; Kim, Y.-J.; Song, K.; Kwon, K. Langmuir 2009, 25, 7140-7147), and the surfaces of the Pt nanoparticles are modified with irreversibly adsorbed Bi. The investigated coverages of $\mathrm{Bi}$ on the Pt nanoparticles are 0.12 and 0.25 as determined by coulometry of the oxidation of adsorbed hydrogen and Bi, and X-ray photoelectron spectroscopy. The cyclic voltammetric behavior of formic acid oxidation reveals that the adsorbed $\mathrm{Bi}$ enhances the catalytic activity of $\mathrm{Pt}$ nanoparticles by impeding a poison-forming dehydration path with a concomitant promotion of a dehydrogenation path. The chronoamperometric results indicate that elemental $\mathrm{Bi}$ and partially oxidized $\mathrm{Bi}$ are responsible for the catalytic enhancement, when the Bi coverages on $\mathrm{Pt}$ nanoparticles are 0.12 and 0.25 , respectively. The size effect of Bi-modified Pt nanoparticles in formic acid oxidation is discussed in terms of specific activity (current per unit surface area) and mass activity (current per unit mass).
\end{abstract}

Key Words: Bismuth, Platinum nanoparticle, Size effect, Formic acid oxidation, Catalytic poison

\section{Introduction}

Formic acid oxidation on Pt electrocatalysts has been investigated to understand electrocatalysis as a model system, as well as in a liquid fuel cell technology as a potential fuel. ${ }^{1,2}$

Oxidation of formic acid is known to take place via a dual path mechanism: dehydrogenation and dehydration. ${ }^{3,4}$ In the dehydrogenation path, a formic acid molecule is oxidized to $\mathrm{CO}_{2}$ and $\mathrm{H}^{+}$directly on Pt electrode surfaces, i.e., $\mathrm{HCOOH} \rightarrow \mathrm{CO}_{2}$ $+2 \mathrm{H}^{+}+2 \mathrm{e}$. On the other hand, the dehydration path allows a formic acid molecule to decompose to $\mathrm{H}_{2} \mathrm{O}$ and a CO-like catalytic poison which is oxidized further to $\mathrm{CO}_{2}$, i.e., $\mathrm{HCOOH} \rightarrow$ $\mathrm{H}_{2} \mathrm{O}+$ poison, and poison $+\mathrm{H}_{2} \mathrm{O} \rightarrow \mathrm{CO}_{2}+2 \mathrm{H}^{+}+2 \mathrm{e}$. The catalytic poison is produced at a lower potential and oxidized at a higher potential than the potential region where the dehydrogenation takes place, so that the poison blocks the surfaces of $\mathrm{Pt}$ available for the dehydrogenation to reduce the catalytic activity. Specifically, the catalytic poison is formed in the hydrogen region and oxidized to $\mathrm{CO}_{2}$ by coupling with oxygenous species, such as the surface hydroxyl group formed near the surface oxidation potential of $\mathrm{Pt}^{2}$

The oxidation of formic acid is affected by the crystallographic differences of the Pt electrode surfaces. ${ }^{5-11}$ Voltammetric studies have revealed that $\mathrm{Pt}(111)$ is less active toward formic acid oxidation than $\operatorname{Pt}(100)$ and $\operatorname{Pt}(110)$ of less dense surface structures. ${ }^{8}$ In addition, the monatomic steps play different roles in the oxidation of formic acid depending on the crystallographic orientation of the Pt single crystal electrode surfaces: ${ }^{9,10}$ the monatomic steps on $\operatorname{Pt}(111)$ decrease catalytic activity by increasing the amount of poison, while those on $\mathrm{Pt}(100)$ and $\mathrm{Pt}(110)$ enhance catalytic performance by reducing the amount of poison. Our group has recently reported that the orders of the surface area specific activities for the oxidation of formic acid, as mea- sured with chronoamperometry are $\operatorname{Pt}(111)>\operatorname{Pt}(100)>\mathrm{Pt}$ nanoparticle $>\operatorname{Pt}($ poly $){ }^{11}$

Modification of Pt electrode surfaces with foreign metals is an important way to enhance the catalytic activity of Pt towards formic acid oxidation. The specific foreign metals that have been investigated as surface modifiers include $\mathrm{Bi},{ }^{12-17} \mathrm{Ru},{ }^{18,19} \mathrm{Pd},{ }^{20,21}$ $\mathrm{Au}^{22}$ and $\mathrm{Sn}^{23} \mathrm{Bi}$ is the most investigated one among the aforementioned foreign metals. Under voltammetric conditions, the catalytic activities of $\mathrm{Pt}(111)$ and $\mathrm{Pt}(100)$ that have been modified with irreversibly adsorbed $\mathrm{Bi}$ have been reported to increase by factors of 40 and 20, respectively. ${ }^{12,13}$ The presence of Bi on Pt electrode surfaces results in a decrease in the amount of catalytic poison ${ }^{14}$ and a cathodic shift of the onset potential. ${ }^{13}$ In the vein of practical applications, various methods to modify $\mathrm{Pt}$ electrode surfaces with Bi have been scrutinized, including alloying ${ }^{15}$ and electrochemical means. ${ }^{16,17}$ On the other hand, Pd on Pt nanoparticles enhances formic acid oxidation, while $\mathrm{Ru}$ on Pt nanoparticles suppresses the desired reaction. ${ }^{19}$ In addition, it is notable that on Pt-Au alloy catalyst, formic acid oxidation takes place via a dehydrogenation route with forming a significant amount of catalytic poison. ${ }^{22}$ Furthermore, Pt nanofeatures spontaneously deposited on $\mathrm{Au}(111)$ have been reported to be very effective in formic acid oxidation by factor of 20 in terms of turnover frequency. ${ }^{24}$

From a more practical point of view, it is certainly worth investigating the enhancement of formic acid oxidation by $\mathrm{Bi}$ on Pt nanoparticles of various sizes. In industrial approaches to fuel cell technology, practical catalysts are nanoparticles dispersed on an appropriate support to increase effective surface area, and thus, mass activity (i.e., current per unit mass); however, as nanoparticle size becomes smaller, the surface area specific activity (i.e., current per unit surface area) varies due to structural changes in populations of atoms at vertices, edges and facets 
such as (111) and (100), ${ }^{25-28}$ and electronic factors induced by structural changes ${ }^{29-33}$ (i.e., "particle size effect"). As the size of a Pt nanoparticle changes, the relative numbers of the Pt atoms at the specific surface environments also change. Thus, it would be reasonable to expect diverse catalytic behavior of Bi-modified Pt nanoparticles as the crystallographic environment (or size) of the Pt nanoparticles is changed, since the effect of Bi greatly depends on the crystallographic morphologies of Pt electrode surfaces as previously mentioned.

Recently, our group has reported two independent works related to the above specific research targets: modification of $\mathrm{Pt}$ nanoparticles with $\mathrm{Bi}^{34}$ and the size effect of $\mathrm{Pt}$ nanoparticles in the oxidation of methanol and formic acid. ${ }^{11}$ Elemental Bi on Pt nanoparticles was found to impede the dehydration path, but also to facilitate dehydrogenation to enhance the catalytic activity in formic acid oxidation by a factor of 4 in the potential range from $-0.1 \mathrm{~V}$ to $0.6 \mathrm{~V}$ (versus $\mathrm{Ag} / \mathrm{AgCl}$ ). It was also observed that partially oxidized $\mathrm{Bi}$ in the potential range from $0.3 \mathrm{~V}$ to $0.7 \mathrm{~V}$ (versus $\mathrm{Ag} / \mathrm{AgCl}$ ) increases the formic acid oxidation activity by a factor of 8 via a direct oxidation route. On the other hand, our recent work on the particle size effect of Pt nanoparticles on formic acid oxidation has revealed that the specific activity for formic acid oxidation does not vary when the Pt particle size ranges from 5.8 to $1.8 \mathrm{~nm}^{11}$

In this work, we present the catalytic enhancement of formic acid oxidation on Bi-modified Pt nanoparticles of various sizes. The surface modification of Pt nanoparticles was carried out using the irreversible adsorption of $\mathrm{Bi}$, and the particle size of the investigated Pt nanoparticles ranged from 5.6 to $1.5 \mathrm{~nm}$. The characteristics of Bi-modified Pt nanoparticles, including Bi coverage, were fully investigated, and their catalytic activities were measured using cyclic voltammetry and chronoamperometry under a hydrodynamic condition. The variation in the catalytic activity of formic acid oxidation is discussed in terms of Bi coverage and $\mathrm{Pt}$ nanoparticle size along with the results associated with $\mathrm{CO}$ and catalytic poison.

\section{Experimental}

Preparation of size-controlled Pt nanoparticles dispersed on platelet carbon nanofiber ${ }^{35}$ (PCNF, supplied from Kyushu University, Japan) was achieved using the polyol method. ${ }^{36}$ The details concerning the provision of Pt nanoparticles of various sizes and the characterization of their physical properties (size distribution, shape and loaded amount) are fully documented in ref. 34. Glycolates, formed during the reduction of Pt ions by ethylene glycol, are a stabilizing agent of Pt nanoparticles, and their concentrations were controlled by the $\mathrm{pH}$ of the reaction medium. The sizes of the cubo-octahedral Pt nanoparticles ranged from 1.5 to $5.6 \mathrm{~nm}$, as confirmed by transmission electron microscopy (TEM, JEM-2010F, JEOL). The loaded amounts of dispersed Pt were $10 \pm 0.5 \mathrm{wt} \%$ of the catalysts, regardless of size, as quantified using the weights of the residues $\left(\mathrm{PtO}_{2}\right)$ after burning off the carbon support measured with a thermal gravimeter (TA instrument, SDT 2960 Simultaneous DTA-TGA).

The surfaces of the Pt nanoparticles were modified using irreversibly adsorbed $\mathrm{Bi}^{34}$ The adsorption of $\mathrm{Bi}$ was carried out by contacting the $\mathrm{Pt}$ nanoparticles with $\mathrm{Bi}^{3+}$ ion-containing solu- tions. The contacting solutions were a $0.5 \mathrm{M} \mathrm{H}_{2} \mathrm{SO}_{4}$ solution (95 - 97\%, Merck) saturated with $\mathrm{Bi}_{2} \mathrm{O}_{3}(99.999 \%$, Sigma Aldrich) and a $0.5 \mathrm{M} \mathrm{H}_{2} \mathrm{SO}_{4}$ solution obtained by diluting the $\mathrm{Bi}_{2} \mathrm{O}_{3}$ saturated $0.5 \mathrm{M} \mathrm{H}_{2} \mathrm{SO}_{4}$ solution by a factor of 20 . The concentration of $\mathrm{Bi}^{3+}$ ion in the $\mathrm{Bi}_{2} \mathrm{O}_{3}$-saturated $0.5 \mathrm{M} \mathrm{H}_{2} \mathrm{SO}_{4}$ solution was approximately $7.0 \mathrm{mM}$. Upon irreversible adsorption of $\mathrm{Bi}$, the adsorbed $\mathrm{Bi}^{3+}$ ions were electrochemically reduced at $0.1 \mathrm{~V}$ (vs. $\mathrm{Ag} / \mathrm{AgCl}$ reference electrode) in a $0.5 \mathrm{M} \mathrm{H}_{2} \mathrm{SO}_{4}$ solution for 30 min. The details regarding the process to modify Pt nanoparticles using irreversible adsorption are available in ref. 34.

In electrochemical measurements, a conventional three-electrode system was employed. The working electrodes employed in this work were prepared by spreading a slurry mixture of Bimodified Pt catalyst, 5\% Nafion solution (Wako), and water, onto a Au disk electrode, followed by drying under an IR lamp. ${ }^{34,37}$ The counter electrode was a Pt gauze, and the reference electrode was a home-made $\mathrm{Ag} / \mathrm{AgCl}$ electrode in $1.0 \mathrm{M} \mathrm{NaCl}$, against which the potential in this work is reported. Two electrochemical measurement techniques were employed: cyclic voltammetry for diagnostic purposes and chronoamperometry for catalytic activity measurements. In particular, it is notable that a rotating disk electrode configuration was utilized during all electrochemical measurements (1000 rpm) to efficiently remove $\mathrm{CO}_{2}$ bubbles. The concentration of formic acid $(99 \%$, Wako) was $2.0 \mathrm{M}$ in the $0.5 \mathrm{M} \mathrm{H}_{2} \mathrm{SO}_{4}$ solution. For $\mathrm{CO}$ adsorption, the working electrodes were immersed into a $0.5 \mathrm{M} \mathrm{H}_{2} \mathrm{SO}_{4}$ solution saturated with a $\mathrm{CO}$ gas $(99.99 \%$, Air Liquid Korea) at $0 \mathrm{~V}$ for $15 \mathrm{~min}$, followed by rinsing with copious amounts of clean electrolyte without losing electrochemical contact. ${ }^{38}$ The formation of the catalytic poison was performed by holding the electrode potential at $0 \mathrm{~V}$ for $15 \mathrm{~min}$ in $2 \mathrm{M}$ formic acid $+0.5 \mathrm{M}$ $\mathrm{H}_{2} \mathrm{SO}_{4}$ solution and rinsing in the same way as in the case of $\mathrm{CO}$ adsorption.

X-ray photoelectron spectroscopic (XPS) measurements were carried out to measure the coverage of Bi (Thermo Electron Co., MultiLab 2000, USA). A monochromatic Mg Ka X-ray beam $(1253.6 \mathrm{eV})$ was utilized as an excitation source, and a multi-channel hemispherical electron energy analyzer was operated at a constant pass energy of $20 \mathrm{eV}$. The observed spectra were curve-fitted using a mixed Gaussian-Lorentzian line shape and Shirley baselines.

\section{Results and Discussions}

Characterization of Bi-modified Pt nanoparticles of various sizes. Figure 1 shows typical TEM images of Pt nanoparticles of various sizes, dispersed on a platelet carbon nanofiber (PCNF). The Pt nanoparticles are homogenously distributed on the carbon support and are uniform in size. The characteristics of the Pt nanoparticles of various sizes have been detailed in a publication from our group. ${ }^{11}$ Briefly, the Pt nanoparticles are cubo-octahedrons consisting of (111) and (100) facets of Pt. In addition, their particle sizes (or mean diameters) decrease from 5.6 to $1.5 \mathrm{~nm}$ as the $\mathrm{pH}$ of the glycol reducing medium increases from 9.7 to 12.5 .

Typical particle size distributions for Pt nanoparticles on $\mathrm{PCNF}$ and a plot of $\mathrm{Pt}$ nanoparticle size as a function of $\mathrm{pH}$ are depicted in Figure S1 of the supporting information.

Figure 2 shows the cyclic voltammograms of Pt nanoparticles 

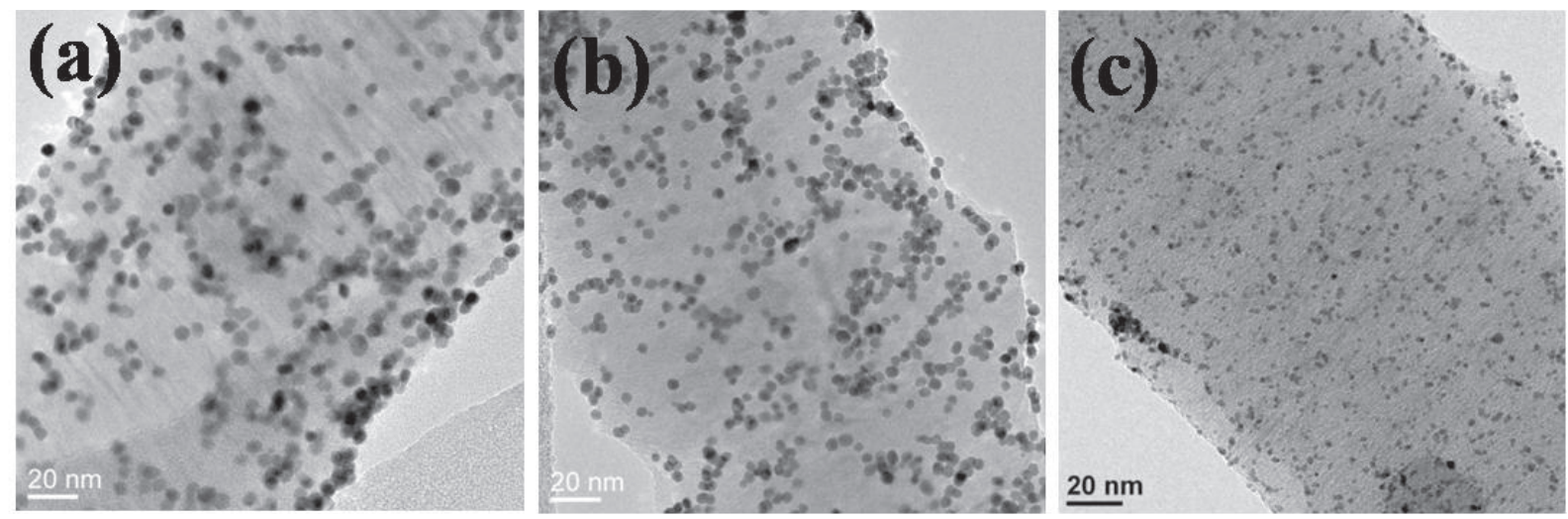

Figure 1. Typical TEM images of Pt nanoparticles dispersed on PCNF: (a) $5.6 \mathrm{~nm}$, (b) $3.0 \mathrm{~nm}$, and (c) $1.5 \mathrm{~nm}$.

(a)
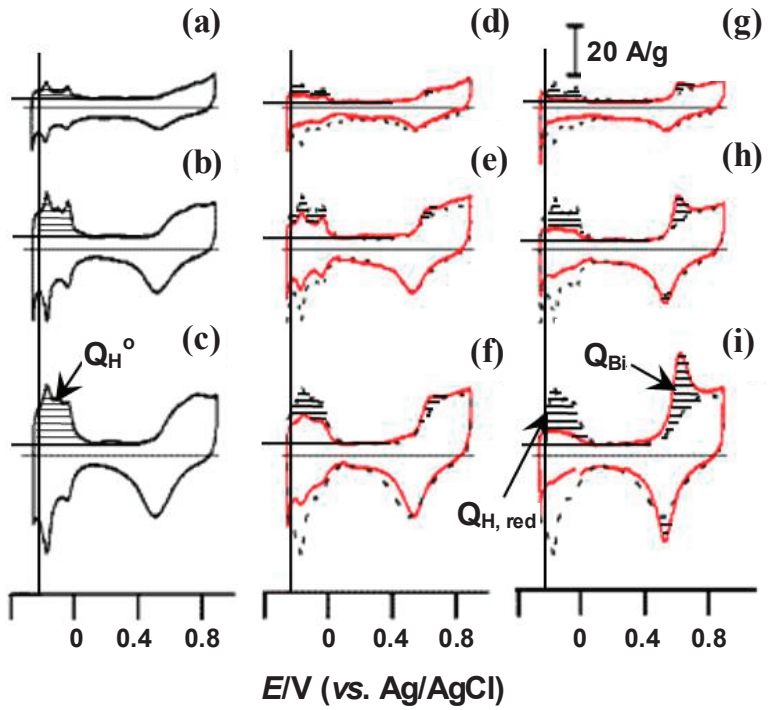

Figure 2. Cyclic voltammograms of Bi-modified Pt nanoparticles in a $0.5 \mathrm{M} \mathrm{H}_{2} \mathrm{SO}_{4}$ solution. The sizes of Pt nanoparticles are $5.6 \mathrm{~nm}$ for (a), (d), and (g); $3.0 \mathrm{~nm}$ for (b), (e), and (h); and $1.5 \mathrm{~nm}$ for (c), (f), and (i). The coverages of Bi on Pt nanoparticles presented in the left, middle, and right panels are $0,0.12$, and 0.25 , respectively. Scan rate: $10 \mathrm{mV} / \mathrm{s}$.

modified with irreversibly adsorbing $\mathrm{Bi}$ in a $0.5 \mathrm{M} \mathrm{H}_{2} \mathrm{SO}_{4}$ solution. The left panel of Figure 2 presents the cyclic voltammograms of plain Pt nanoparticles of selected sizes. As the particle size increases from 1.5 to $5.6 \mathrm{~nm}$, the charge of the hydrogen region decreases, which is certainly predictable because of the decrease in surface area. The right panel of Figure 2 depicts the cyclic voltammograms of Pt nanoparticles obtained after being contacted with a $\mathrm{Bi}_{2} \mathrm{O}_{3}$-saturated solution $(\sim 7 \mathrm{mM})$ for $30 \mathrm{~min}$ and processed as described in the experimental section of this manuscript. For a clear comparison, the cyclic voltammograms of plain Pt nanoparticles (dashed lines) are displayed together. The oxidation and reduction peaks of irreversibly adsorbed $\mathrm{Bi}$ clearly appear at 0.6 and $0.5 \mathrm{~V}$, respectively, accompanied with a simultaneous decrease in hydrogen charges. It should be emphasized that the charge relevant to Bi depends on the sizes of the Pt nanoparticles. The middle panel of Figure 2 represents cyclic voltammograms of Pt nanoparticles after contact with the $\sim 0.35$ $\mathrm{mM} \mathrm{Bi}^{3+}$ ion-containing solution. In the voltammograms, the

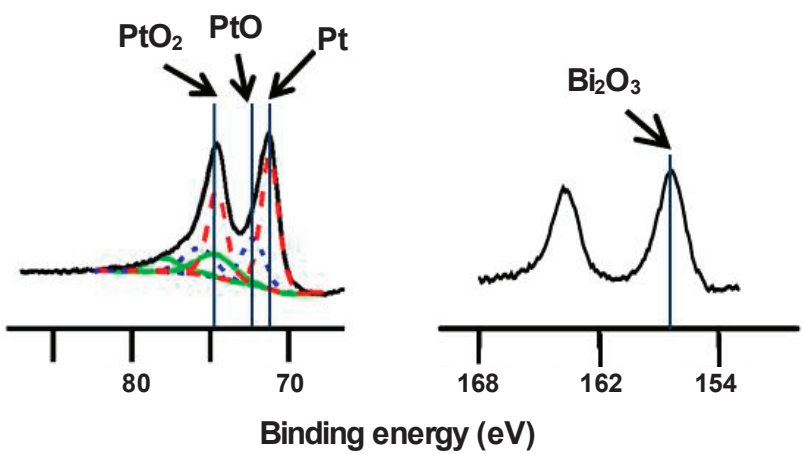

Figure 3. X-ray photoelectron spectra of Pt nanoparticles $(5.6 \mathrm{~nm})$ with a Bi coverage of 0.25 in the regions of (a) Pt $4 f$ and (b) Bi $4 f$ region.

charges of the Bi redox couple are sparingly observed, although the specific decrease of hydrogen charge is notable. Here again, the charges of $\mathrm{Bi}$ and $\mathrm{H}$ depend on the sizes of the Pt nanoparticles.

Coverages of $\mathrm{Bi}$ on Pt nanoparticles were independently measured using the charges related to hydrogen adsorption/desorption and $\mathrm{Bi}$ oxidation. A ratio of the number of $\mathrm{Bi}$ atoms to that of surface Pt atoms is defined as the coverage of $\mathrm{Bi}\left(\theta_{\mathrm{Bi}}\right)$. Also, the cyclic voltammogram of plain Pt nanoparticles of a certain size was utilized as a background to estimate any change in the charges of the hydrogen region and the Bi oxidation observed on the Bi-modified Pt nanoparticles of a particular size. The number of surface $\mathrm{Pt}$ atoms is estimated using the hydrogen charge $\left(\mathrm{Q}_{\mathrm{H}}{ }^{ }\right)$, e.g., the hatched part of Figure 2(c). The number of $\mathrm{Bi}$ atoms is calculated using the charge of $\mathrm{Bi}$ oxidation $\left(\mathrm{Q}_{\mathrm{Bi}}\right)$ and the reduced charge of hydrogen region $\left(\mathrm{Q}_{\mathrm{H}, \mathrm{red}}\right)$, as illustrated in Figure 2(i). Specifically, the coverage of $\mathrm{Bi}\left(\theta_{\mathrm{Bi}}\right)$ is estimated using the equations of $\theta_{\mathrm{Bi}}=\mathrm{Q}_{\mathrm{Bi}} / 3 \mathrm{Q}_{\mathrm{H}}{ }^{\circ}$ and $\theta_{\mathrm{Bi}}=\mathrm{Q}_{\mathrm{H}, \text { red }} / 3 \mathrm{Q}_{\mathrm{H}}{ }^{\mathrm{O}}$. The particular equations using $\mathrm{Q}_{\mathrm{Bi}}$ and $\mathrm{Q}_{\mathrm{H}, \text { red }}$ are based on assumptions that three electrons are involved in the Bi redox reaction and that one Bi atom blocks three hydrogen adsorption sites, respectively. ${ }^{39}$ The average coverages of $\mathrm{Bi}$ are $0.12 \pm 0.02$ and $0.26 \pm 0.02$, when the Bi concentrations of the contacting solutions are $\sim 0.35$ and $\sim 7 \mathrm{mM}$, respectively. The 0.26 coverage of $\mathrm{Bi}$ on the Pt nanoparticles prepared in this work is the maximum coverage as observed on the Pt nanoparticles in ref. 34 .

XPS measurements were carried out to estimate atomic ratios 
Table 1. Comparison of the atomic ratios of Bi to Pt as measured with electrochemical and spectroscopic means.

\begin{tabular}{|c|c|c|c|}
\hline \multirow{2}{*}{$\begin{array}{l}\text { particle size } \\
\text { (nm) }\end{array}$} & \multirow{2}{*}{$\begin{array}{l}\text { concentration } \\
\text { of } \mathrm{Bi}(\mathrm{mM})\end{array}$} & \multicolumn{2}{|c|}{ atomic ratio of $\mathrm{Bi}$ to $\mathrm{Pt}$} \\
\hline & & electrochemical $^{a}$ & spectroscopic \\
\hline \multirow{2}{*}{5.6} & 0.35 & $0.11 \pm 0.02$ & 0.17 \\
\hline & 7 & $0.23 \pm 0.03$ & 0.23 \\
\hline \multirow{2}{*}{3} & 0.35 & $0.12 \pm 0.01$ & 0.12 \\
\hline & 7 & $0.26 \pm 0.01$ & 0.24 \\
\hline \multirow{2}{*}{1.5} & 0.35 & $0.13 \pm 0.01$ & 0.13 \\
\hline & 7 & $0.25 \pm 0.01$ & 0.21 \\
\hline
\end{tabular}

${ }^{a}$ Electrochemical atomic ratio is equivalent to coverage of $\mathrm{Bi}$.

$\theta_{\mathrm{Bi}}=0$

(a)

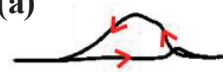

(b)
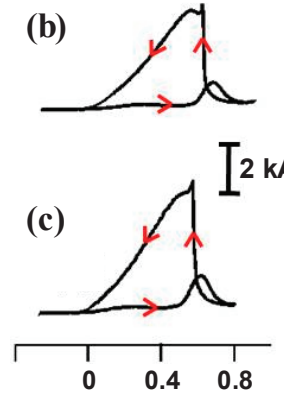

$\theta_{\mathrm{Bi}}=0.12$

(d)

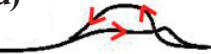

(e)
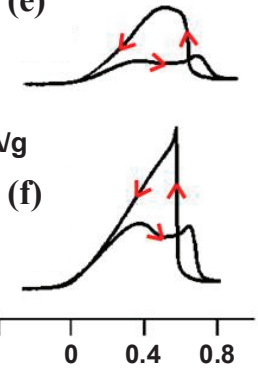

$\mathrm{E} / \mathrm{V}$ (vs. $\mathrm{Ag} / \mathrm{AgCl})$
$\theta_{\mathrm{Bi}}=0.25$ (g)

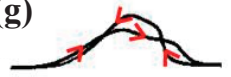

(h)

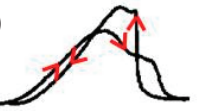

(i)

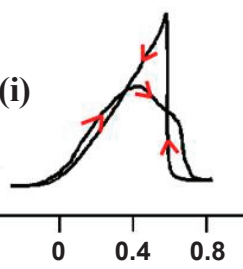

Figure 4. Cyclic voltammograms of formic acid oxidation on Bi-modified Pt nanoparticles in a $2 \mathrm{M}$ formic acid $+0.5 \mathrm{M} \mathrm{H}_{2} \mathrm{SO}_{4}$ solution. The sizes of Pt nanoparticles are $5.6 \mathrm{~nm}$ for (a), (d), and (g); $3.0 \mathrm{~nm}$ for (b), (e), and (h); and $1.5 \mathrm{~nm}$ for (c), (f), and (i). The coverages of Bi on Pt nanoparticles presented in the left, middle, and right panels are $0,0.12$ and 0.25 , respectively. Scan rate: $10 \mathrm{mV} / \mathrm{s}$.

of Bi to Pt. Figure 3 shows typical X-ray photoelectron spectra of Pt $4 f$ and $\mathrm{Bi} 4 f$ of $\mathrm{Pt}$ nanoparticles of $5.6 \mathrm{~nm}$ in size after contacting with a $7 \mathrm{mM}$ Bi solution. In Figure 3(a), the chemical states of $\mathrm{Pt}$ are metallic $\mathrm{Pt}, \mathrm{PtO}$, and $\mathrm{PtO}_{2}$, whose binding energies of Pt $4 f_{7 / 2}$ peaks are $71.4,72.7$, and $74.6 \mathrm{eV}$, respectively. The chemical state of adsorbed $\mathrm{Bi}$ on Pt nanoparticles is solely $\mathrm{Bi}_{2} \mathrm{O}_{3}$ as reflected by the binding energy of $\mathrm{Bi} 4 f_{5 / 2}\left(158.7 \mathrm{eV}^{40}\right)$ (Figure 3(b)). Here again, the existence of oxygen on Bi-modified Pt nanoparticles is obviously due to air exposure during the preparation procedure. The atomic ratios of $\mathrm{Bi}$ were semi-quantitatively estimated using the peak areas of $\mathrm{Pt} 4 f_{7 / 2}$ and $\mathrm{Bi} 4 f_{5 / 2}$, whose relative sensitivities are 2.55 and 4.25 , respectively. ${ }^{41}$

The atomic ratios of Bi to Pt observed in Bi-modified Pt nanoparticles of selected sizes estimated by the two different methods are compared in Table 1. It should be pointed out that because the sampling depth of the spectroscopic method is roughly 1 $\mathrm{nm},{ }^{41}$ the electrochemical ratio (i.e., coverage) would differ from the spectroscopic one. Despite the fact that all of the values measured with the two different methods are not exactly matched, the observed divergence is reasonable, and furthermore, (a)

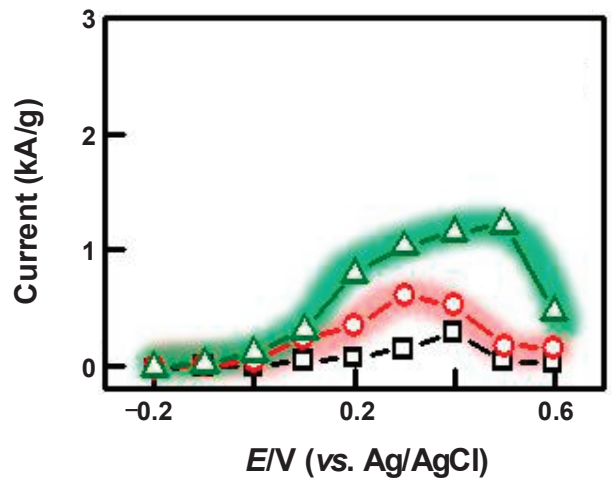

(b)

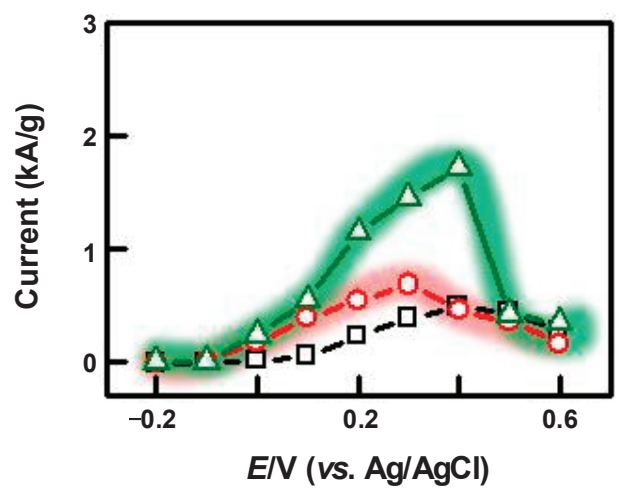

(c)

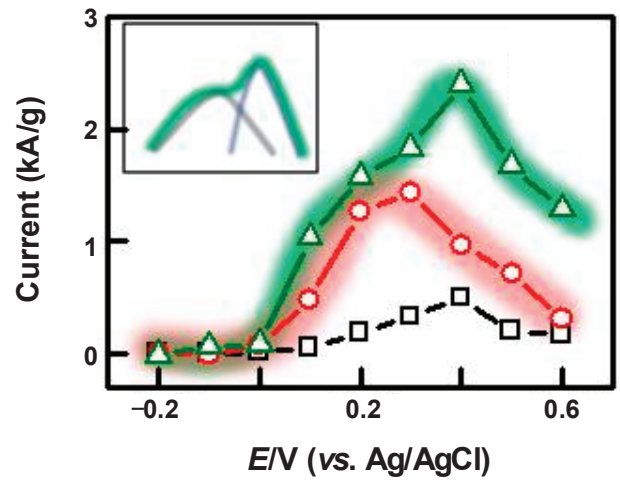

Figure 5. Chronoamperometric current of formic acid oxidation on Bimodified Pt nanoparticles as a function of potential. The oxidation currents were measured using chronoamperometry in $2.0 \mathrm{M}$ formic acid $+0.5 \mathrm{M} \mathrm{H}_{2} \mathrm{SO}_{4}$ solution under a rotating speed of $1000 \mathrm{rpm}$. The sizes of Pt nanoparticles are (a) $5.6 \mathrm{~nm}$, (b) $3.0 \mathrm{~nm}$, and (c) $1.5 \mathrm{~nm}$. Bi coverages are $(\square) 0,(\circ) 0.12$, and $(\triangle) 0.25$. The inset in (c) is an illustration of the deconvolution of the current-potential profile observed on Pt nanoparticles modified with Bi with a coverage of 0.25 .

we believe that the overall divergence should be roughly $10 \%$. This particular divergence comes from the preparation of $\mathrm{Bi}$ modified Pt nanoparticles, and not from the measurements. Thus, the entire procedure of Pt nanoparticle modification using the irreversible adsorption of Bi used in this work retains a $10 \%$ random error. Even though slight divergences in the determination of Bi coverage are discussed, Bi coverages of 0.25 and 0.12 will be used in the following text for the Pt nanoparticles modified using Bi solutions of $\sim 7 \mathrm{mM}$ and $\sim 0.35 \mathrm{mM}$, respectively.

Oxidation of formic acid on Bi-modified Pt nanoparticles of various sizes. Figure 4 shows cyclic voltammograms of formic acid oxidation on Bi-modified Pt nanoparticles of various sizes 
in $2 \mathrm{M}$ formic acid $+0.5 \mathrm{M} \mathrm{H}_{2} \mathrm{SO}_{4}$ solution. The left panel of Figure 4 represents the oxidative behavior of formic acid on plain Pt nanoparticles. Regardless of nanoparticle size, the anodic current profiles observed on the plain Pt nanoparticles are not significant, indicating that catalytic poisoning is serious, especially during the anodic scan. Upon reversal of the scan direction, the oxidative current of formic acid increasing dramatically at the potential of surface Pt oxide reduction $(0.65 \mathrm{~V})$, implying that the dehydrogenation could occur promptly on a metallic $\mathrm{Pt}$ surface not covered with catalytic poison. Furthermore, the cathodic currents are notably enhanced as the size decreases. For example, the peak current observed on Pt nanoparticles of 1.5 $\mathrm{nm}$ in size is larger than that on Pt nanoparticles of $5.6 \mathrm{~nm}$ in size by a factor of 1.8. When the Pt nanoparticles are covered with $\mathrm{Bi}$, a significant enhancement of anodic oxidative current of formic acid becomes obvious, as shown in the middle and right panels of Figure 4 . The anodic current appears in the potential region of $0.3-0.4 \mathrm{~V}$, and the enhancement factor in the anodic current depends on Bi coverage: roughly 3 and 5 for Bi coverages of 0.12 and 0.25 , respectively. In addition, the onset potential on the Bi-modified Pt nanoparticles is about $0.15 \mathrm{~V}$ less positive than that on the plain Pt nanoparticles. This observation strongly reveals that the changes in voltammetric behavior on Bi-modified Pt nanoparticles are ascribable to the promotion of the dehydrogenation path, i.e., the direct oxidation to $\mathrm{CO}_{2}$, accompanied with inhibition of the dehydration route to form catalytic poison.

Figure 5 shows plots of potential versus chronoamperometric currents of formic acid oxidation on Pt nanoparticles of selected sizes. The chronoamperometric currents were measured at 30 min after a potential jump from $-0.25 \mathrm{~V}$ to a potential of interest using a rotating disk electrode configuration at a $1000 \mathrm{rpm}$ rotating speed. The oxidative currents of formic acid reached to a steady-state within 30 min, as demonstrated in Figure S2 of supporting information, and the steady-state currents at several potentials are plotted in Figure 5.

The current-potential profiles of formic acid oxidation in Figure 5 clearly depend on Bi coverage and the size of Pt nanoparticles. On plain Pt nanoparticles, the maximum oxidative currents appear at $0.4 \mathrm{~V}$, and the value increases as the particle size decreases. ${ }^{11}$ Specifically, the increment of the maximum current is roughly 2 when the size decreases from $5.6 \mathrm{~nm}$ to $1.5 \mathrm{~nm}$. The presence of Bi induces significant changes in the current-potential profiles. When the Bi coverage is 0.12 , the oxidative currents are larger than those on plain Pt nanoparticles at each corresponding potential, and the potential of current maximum shifts from $0.4 \mathrm{~V}$ to $0.3 \mathrm{~V}$. Further increases in Bi coverage to 0.25 leads to an additional increase in the oxidative current; however, in the current-potential profiles, there are two current maxima at $0.2 \mathrm{~V}$ and $0.4-0.5 \mathrm{~V}$. As shown in the inset of Figure 5(c), the current-potential profile could be decoupled into two peaks, as performed in our previous report on the modification of a commercial Pt nanoparticle catalysts with $\mathrm{Bi}^{34}$ The existence of the two specific current maxima at different potential regions on the Bi-modified Pt electrodes implies that the enhancing catalytic pathways under the influence of Bi depend on the coverage of $\mathrm{Bi}$ and the oxidation potential (see below). Another point to be clarified is that that the onset potentials of formic acid oxidation on the Bi-modified Pt nanoparticles are approxi-

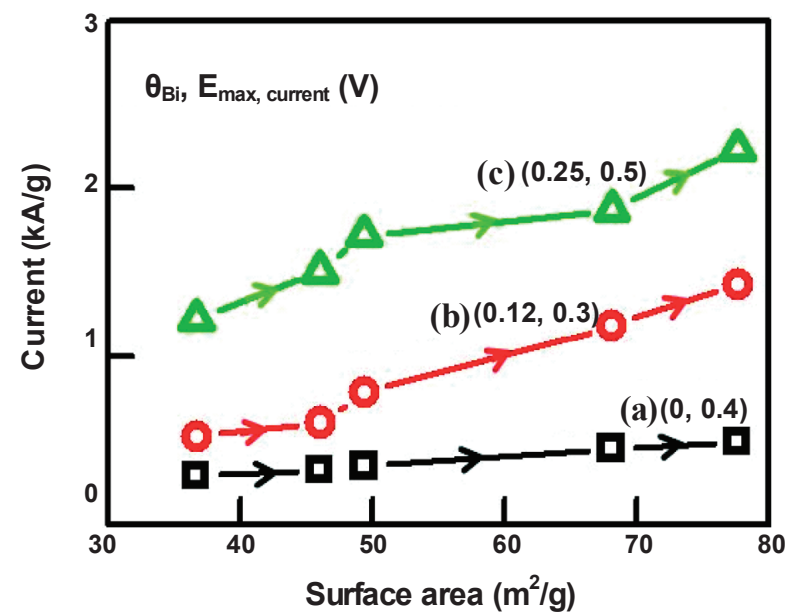

Figure 6. Plots of mass activity of formic acid oxidation on Bi-modified Pt nanoparticles $v s$ surface area. The inset table stands for the Bi coverage $\left(\theta_{\mathrm{Bi}}\right)$ and the potential $(\mathrm{E}$ in $\mathrm{V})$ of the maximum currents presented in Figure 5. The particle sizes are 5.6, 4.0, 3.0, 1.8, and $1.5 \mathrm{~nm}$ in the order as indicated with the arrows in each line.

mately $0.2 \mathrm{~V}$ lower than those observed on the plain ones. Thus, $\mathrm{Bi}$ on Pt nanoparticles increases the catalytic performance of Pt towards formic acid oxidation. On the other hand, as the size of Pt nanoparticles decreases, the catalytic activity in terms of mass increases due to the increase in surface area. Regardless of the particle size, the enhancement factors are $2-3$ and $\sim 5$ when the Bi coverages are 0.12 and 0.25 , respectively.

Figure 6 shows plots of mass-specific current versus electrochemically measured surface area of Pt nanoparticles modified with Bi. The currents in Figure 6 are the maximum currents in Figure 5, depending on Bi coverage, so that the potentials for each line in Figure 5 are different. Specifically, the potentials of the current maxima in Figure 5 are $0.4 \mathrm{~V}$ for $\theta_{\mathrm{Bi}}=0,0.3 \mathrm{~V}$ for $\theta_{\mathrm{Bi}}=0.12$, and $0.5 \mathrm{~V}$ for $\theta_{\mathrm{Bi}}=0.25$. In addition, a few issues should be clarified before further discussion (for details concerning this kind of plot, refer to ref. 11). The surface areas of the Bimodified Pt nanoparticles are those of the plain Pt nanoparticles, and are estimated using the charges of hydrogen desorption in Figure 2. The plots in Figure 6 demonstrates a variation of mass activity as a function of surface area, which is determined by the size in turn (here, mass activity and specific activity versus size are shown in Figure S3 and Figure S4, respectively.). On the other hand, the linearity of the plot depicted in Figure 6 implies that the specific activity does not depend on the nanoparticle size; in the case of non-linearity, a serious modification in catalytic behavior takes place as the size varies. In addition, if a catalyst shows a linear plot in a certain range of particle sizes, the slope therein refers to the specific activity in the specific size regime.

In Figure 6, Pt nanoparticles of various sizes show fairly linear plots in the regime of $5.6-1.5 \mathrm{~nm}$ in diameter, depending on $\mathrm{Bi}$ coverage. The enhancement factor due to the presence of $\mathrm{Bi}$ clearly increases in terms of mass activity from 4 for $5.6 \mathrm{~nm}$ to 5 for $1.5 \mathrm{~nm}$. On the other hand, the slope (i.e., the specific activity) of plain Pt nanoparticles is $5.1 \mathrm{~A} / \mathrm{m}^{2}$. On Bi-modified Pt nanoparticle surfaces, the slope increases to 22.9 and $22.8 \mathrm{~A} / \mathrm{m}^{2}$ when Bi coverages are 0.12 and 0.25 , respectively. In terms of specific activity, irreversibly adsorbed $\mathrm{Bi}$ increases the catalytic 
co

(a)

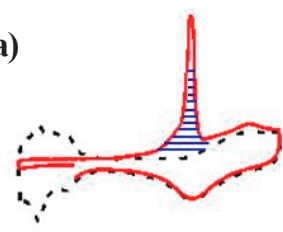

(c)

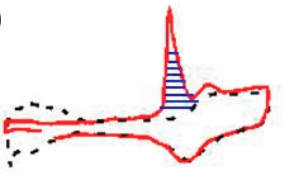

(e)

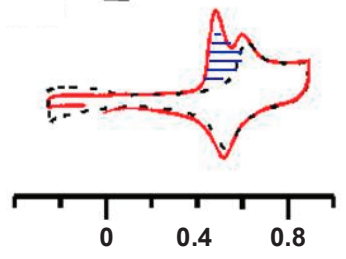

Catalytic poison

(b)

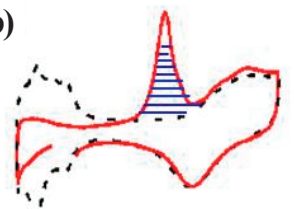

(d)

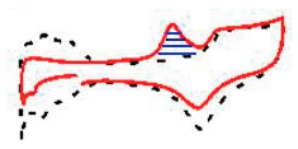

(f) $\lceil 15 \mathrm{~A} / \mathrm{g}$

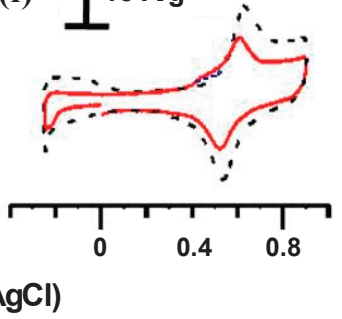

Figure 7. Stripping voltammograms of adsorbed $\mathrm{CO}$ and catalytic poison on Bi-modified Pt nanoparticles of $1.5 \mathrm{~nm}$ in size in a $0.5 \mathrm{M} \mathrm{H}_{2} \mathrm{SO}_{4}$ solution. The coverages of Bi on Pt nanoparticles are (a) 0 , (b) 0.12 , and (c) 0.25 . Scan rate: $10 \mathrm{mV} / \mathrm{s}$.

activity of Pt nanoparticles toward formic acid oxidation by roughly a factor of 5 . Thus, it is clear that the increase in the mass activity of plain Pt nanoparticles is simply due to the increase in surface area as the Pt nanoparticles become smaller, as previously reported by us. ${ }^{11}$ Furthermore, this specific trend in variation of mass activity and specific activity of formic acid oxidation holds for Pt nanoparticles modified with irreversibly adsorbed $\mathrm{Bi}$. From a practical point of view (or in terms of Pt mass), therefore, smaller Pt nanoparticles modified with Bi are more efficient in formic acid oxidation; however, it should be reminded that when the Pt nanoparticles are smaller than $1.5 \mathrm{~nm}$, they aggregate to reduce catalytic efficiency. ${ }^{11}$

The stripping of $\mathrm{CO}$ and catalytic poison on Bi-modified Pt nanoparticles of various sizes. Figure 7 shows stripping voltammograms of $\mathrm{CO}$ and catalytic poison on Bi-modified Pt nanoparticles of $1.5 \mathrm{~nm}$ in size. In the calculation of the stripping charges on the Bi-modified Pt nanoparticles, the anodic voltammogram in the absence of adsorbed $\mathrm{CO}$ and poison (dashed voltammograms in Figure 7) was used as a background. The stripping charges of $\mathrm{CO}$ and poison decrease as $\mathrm{Bi}$ coverage increases, because the adsorbed $\mathrm{Bi}$ inhibits the adsorption of $\mathrm{CO}$ and poison formation; however, the stripping voltammograms of $\mathrm{CO}$ on Bi-modified Pt nanoparticles are slightly different from those of catalytic poisons. Specifically, the peak potential of CO stripping behavior on plain Pt nanoparticles is $0.5 \mathrm{~V}$ (Figure 7(a)), whereas the peak potential of poison stripping is $0.4 \mathrm{~V}$ (Figure 7(b)). This means that the adsorbed $\mathrm{CO}$ is not exactly identical to the catalytic poison from the formic acid: the adsorbed $\mathrm{CO}$ is oxidized when the $\mathrm{Bi}$ is oxidized, whereas the poison is oxidized before the $\mathrm{Bi}$ is oxidized. ${ }^{34}$

Figure 8 shows variations of $\mathrm{CO}$ and catalytic poison stripp-

(a)

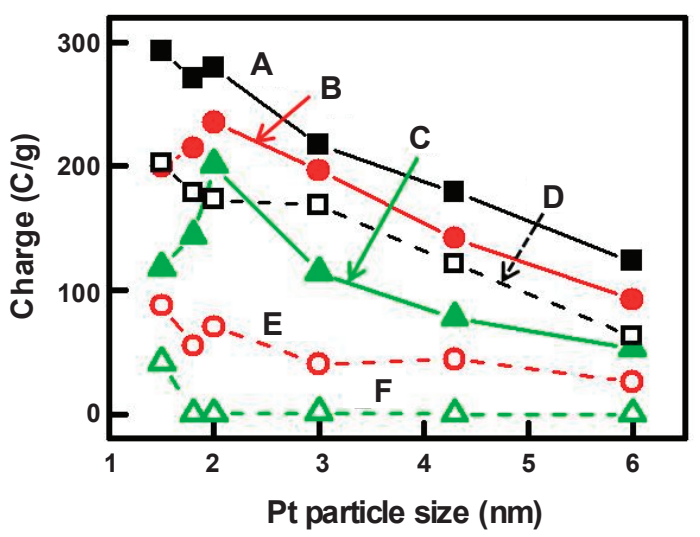

(b)

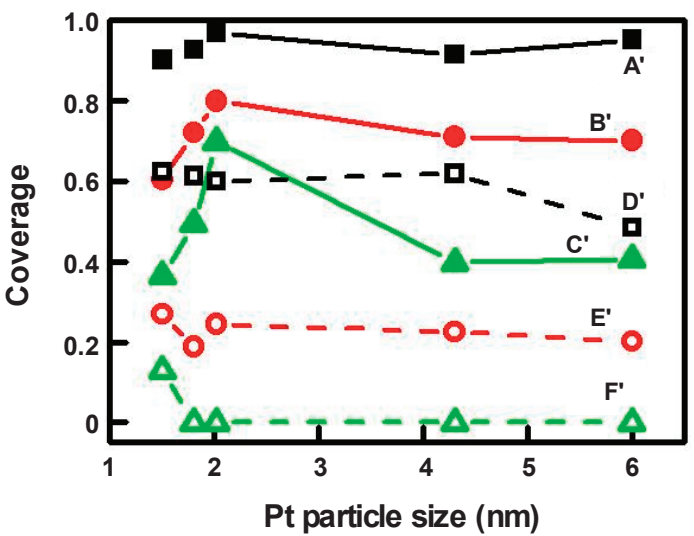

Figure 8. The variation of (a) stripping charges and (b) coverages of $\mathrm{CO}$ and catalytic poison as a function of $\mathrm{Pt}$ nanoparticle size. Solid lines (filled symbols) and dashed lines (open symbols) represent the stripping charges and coverages of $\mathrm{CO}$ and poison, respectively. $\mathrm{Bi}$ coverages are $(\mathbf{\square}, \square) 0,(\bullet, \circ) 0.12$, and $(\Delta, \triangle) 0.25$.

ing charges and their coverages as a function of Pt nanoparticle size. The coverages of $\mathrm{CO}$ and poison are the ratios of the $\mathrm{CO}$ and poison stripping charges to the hydrogen charge of the plain $\mathrm{Pt}$ nanoparticles of corresponding size (i.e., $\mathrm{Q}_{\mathrm{H}}{ }^{\mathrm{o}}$ in Figure 2).

The adsorptive behavior of $\mathrm{CO}$ depends on Pt nanoparticle size and Bi coverage. On plain Pt nanoparticles, the stripping charge of adsorbed $\mathrm{CO}$ increases as the particle size decreases (line A in Figure 8(a)). A similar variation in the amount of CO stripping charge on the Bi-modified Pt nanoparticles is discernable except for sudden decreases when the size is smaller than $2.0 \mathrm{~nm}$ (line B and C in Figure 8(a)). Such a sudden decrease in the amount of $\mathrm{CO}$ on relatively small Pt nanoparticles may be related to the abrupt changes in the numbers of Pt atoms at vertices, edges and single crystal facets such as (111) and (100); ${ }^{11}$ however, the coverages of $\mathrm{CO}$ on plain Pt nanoparticles remain fairly constant to be 0.9 as shown in Figure 8(b). The reported values of CO coverage on Pt nanoparticles $\left(0.9,{ }^{42} 1.0,{ }^{42}\right.$ and $\left.1.2^{43}\right)$ are rather divergent, which may come from the difficulty in determining the cathodic potential limit of the hydrogen region. ${ }^{44} \mathrm{In}$ addition, the relatively constant coverage regardless of Pt nanoparticle size indicates that as the size becomes smaller, the surface area grows to be geometrically lager. On Bi-modified Pt nanoparticles, the amounts of adsorbed $\mathrm{CO}$ depend on $\mathrm{Bi}$ coverage. Specifically, the stripping charges of $\mathrm{CO}$ per unit mass of 
Pt decreases by approximately 10 and $20 \%$ of that on plain Pt nanoparticles, when the Bi coverage is 0.12 and 0.25 , respectively. In terms of coverage, however, the amount of $\mathrm{CO}$ decreases to roughly $80 \%$ and $40 \%$ of that on plain Pt nanoparticles, when the Bi coverage is 0.12 and 0.25 , respectively. A similar behavior concerning the decrease of $\mathrm{CO}$ coverage in the presence of $\mathrm{Bi}$ has been reported on $\mathrm{Pt}(111)$ electrode surfaces. ${ }^{45}$

The formation of catalytic poison from formic acid depends on Pt nanoparticle size and Bi coverage. On plain Pt nanoparticles, the amount of poison per unit Pt mass (line D in Figure 8(a)) is approximately $60 \%$ of the amount of adsorbed $\mathrm{CO}$. The presence of Bi on Pt nanoparticles more rapidly decreases the amount of poison. When the Bi coverages are 0.12 and 0.25 , the amount of poisons are $\sim 30 \%$ and $0 \%$ of the $\mathrm{CO}$ adsorbed on the respective Bi-modified $\mathrm{Pt}$ nanoparticles. The specific values for the relative amount of poison to $\mathrm{CO}$ are valid in terms of coverage, also, as shown in Figure 8(b). Because the numbers of adsorbed $\mathrm{CO}$ and poison are indicative of the number of electrochemically active $\mathrm{Pt}$ atoms and dehydration reaction sites, it would be logical to claim that $\mathrm{Bi}$ on $\mathrm{Pt}$ nanoparticles prohibits the formation of poison from formic acid, and thus the dehydration path of formic acid.

A naturally arising question concerns the dehydrogenation path in formic acid oxidation. Since the amount of poison on plain Pt nanoparticles is $60 \%$ of that of $\mathrm{CO}$, the remaining $40 \%$ of the Pt surface may be available for the dehydrogenation reaction. However, the absence of oxidative current in the anodic scan on plain Pt nanoparticles strongly supports the notion that the remaining Pt surface is not available to the dehydrogenation route. Accordingly, the dehydrogenation path may require a continuous Pt ensemble of a certain but unknown, exact size. The Pt surface modified with Bi then may be efficient for dehydrogenation, but inefficient for dehydration, as revealed by the significant oxidative current during the anodic scan (Figure 4). Thus, the increase in the formic acid oxidation current, especially in the anodic scan, would be due to an increase in the number of reactions possible for dehydrogenation, but not possible for dehydration.

Combining the information in Figure 8 with the cyclic voltammetric and chronoamperometric results, two aspects regarding the role of $\mathrm{Bi}$ in formic acid oxidation are clear. One is that when the coverage of $\mathrm{Bi}$ is low, the dehydration path to catalytic poison is deactivated with simultaneous activation of the dehydrogenation path. Because the dehydration path is activated in the potential range below $0.51 \mathrm{~V}$ (i.e., the onset potential of $\mathrm{Bi}$ oxidation), the metallic $\mathrm{Bi}$ adatoms do not operate in a bifunctional mechanism to remove the catalytic poisons produced by the dehydration path. The other aspect is that at high Bi coverage, the enhancement is notable in the potential range of $0.4-0.6$ $\mathrm{V}$. Because the Bi adatoms are at least partially oxidized in the specific potential range (Figure 2), and because no poison is formed on the Pt nanoparticles with high Bi coverage (Figure 8), an operating oxidation path would be different from the dehydration and/or dehydrogenation paths working on metallic $\mathrm{Bi}$ adlayers. The most probable route for formic acid oxidation on the Pt nanoparticles with high $\mathrm{Bi}$ coverage is a direct oxidation of formic acid not involving catalytic poison as proposed by us. $^{34}$

\section{Conclusions}

Irreversibly adsorbed $\mathrm{Bi}$ on $\mathrm{Pt}$ nanoparticles of various particle sizes enhances formic acid oxidation. When the Bi coverage is around 0.12, the enhancement is achieved on elemental Bi by prohibiting the dehydration path and simultaneously activating the dehydrogenation path. On the other hand, the formic acid oxidation current increases on partially oxidized Bi via a direct oxidation route without forming a catalytic poison, when the Bi coverage is 0.25 .

As the particle size of Pt nanoparticles decreases, the mass activity of the Bi-modified Pt nanoparticles increases. However, the specific activity as measured in the plots of mass activity versus surface area is constant, revealing that the increase in the mass activity comes from a simple increase in geometrical surface area as the Pt nanoparticles become smaller.

The specific activities of the Bi-modified Pt nanoparticles are enhanced by a factor of more than 5 in comparison to plain $\mathrm{Pt}$ nanoparticles. Thus, it would be conclusive that smaller Pt nanoparticles modified with $\mathrm{Bi}$ would be more efficient in terms of mass activity.

Acknowledgments. This work was financially supported by Korean Institute of Science and Technology (contract number: 2E20670-08-081). The authors appreciate the permission of Center for Research Facilities, Chungnam National University, to the instrument of X-ray Photoelectron Spectroscopy used in this work. Jandee Kim was supported by Brain Korea 21 program.

Supporting Information Available. Particle size distributions of Pt nanoparticles, typical chronoamperograms of formic acid oxidation on Bi-modified Pt nanoparticle, and variation of activity as a function of Pt nanoparticle size. The supporting information are available on request from the correspondence author (Fax:+82-42-821-8896; E-mail: ckrhee@cnu.ac.kr).

\section{References}

1. Parsons, R.; Vandernoot, T. J. Electroanal. Chem. 1988, 257, 9.

2. Feliu, J. M.; Herrero, E. Handbook of Fuel Cells; John Wiley \& Sons Ltd.: New York, 2003; Vol. 2.

3. Capon, A.; Parsons, R. J. Electroanal. Chem. 1973, 44, 1.

4. Capon, A.; Parsons, R. J. Electroanal. Chem. 1973, 45, 205.

5. Clavilier, J.; Parsons, R.; Durand, R.; Lamy, C.; Leger, J. M. J. Electroanal. Chem. 1981, 124, 321.

6. Adzic, R. R.; Tripkovic, A. V.; O'Grady, W. Nature 1982, 296, 137.

7. Lamy, C.; Leger, J. M.; Clavilier, J.; Parsons, R. J. Electroanal. Chem. 1983, 150, 321.

8. Motoo, S.; Furuya, N. J. Electroanal. Chem. 1985, 184, 303.

9. Smith, S. P. E.; Ben-Dor, K. F.; Abrua, H. D. Langmuir 1999, 15 , 7325.

10. Herrero, E.; Climent, V. T.; Feliu, J. M. Electrochem. Commun. 2000, 2, 636.

11. Rhee, C. K.; Kim, B.-J.; Ham, C.; Kim, Y.-J.; Song, K.; Kwon, K. Langmuir 2009, 25, 7140.

12. Clavilier, J.; Femandez-Vega, A.; Feliu, J. M.; Aldaz, A. J. Electroanal. Chem. 1989, 261, 113.

13. Clavilier, J.; Fernandez-Vega, A.; Feliu, J. M.; Aldaz, A. J. Electroanal. Chem. 1989, 258, 89. 
14. Fernandez-Vega, A.; Feliu, J. M.; Aldaz, A.; Clavilier, J. J. Electroanal. Chem. 1989, 258, 101.

15. Roychowdhury, C.; Matsumoto, F.; Mutolo, P. F.; Abruna, H. D.; Disalvo, F. J. Chem. Mater. 2005, 17, 5871.

16. Kang, S.; Lee, J.; Lee, J. K.; Chung, S.-Y.; Tak, Y. J. Phys. Chem. $B$ 2006, 110, 7270 .

17. Daniele, S.; Bergamin, S. Electrochem. Commun. 2007, 9, 1388.

18. Gasteiger, H. A.; Markovic, N.; Ross, P. N.; Cairns, E. J. Electrochim. Acta 1994, 39, 1825.

19. Waszczuk, P.; Barnard, T. M.; Rice, C.; Masel, R. I.; Wieckowski, A. Electrochem. Commun. 2002, 4, 599.

20. Llorca, M. J.; Feliu, J. M.; Aldaz, A.; Clavilier, J. J. Electroanal. Chem. 1994, 376, 151.

21. Baldauf, M.; Kolb, D. M. J. Phys. Chem. 1996, 100, 11375.

22. Choi, J. H.; Jeong, K. J.; Dong, Y.; Han, J.; Lim, T. H.; Lee, J. S.; Sung, Y. E. J. Power Sources 2006, 163, 71.

23. Motoo, S.; Watanabe, M. J. Electroanal. Chem. 1976, 69, 429.

24. Kim, J.; Jung, C.; Rhee, C. K.; Lim, T.-H. Langmuir 2007, 23, 10831.

25. Kinoshita, K. Electrochemical Oxygen Technology; John Wiley \& Sons, Inc: New York, 1992.

26. Benfield, R. E. J. Chem. Soc. Faraday Trans. 1992, 88, 1107.

27. Montejano-Carrizales, J. M.; Aguilera-Granja, F.; Lopez, J. L. M. Nanostruct. Mater. 1997, 8, 269.

28. Jr, P. N. R. Handbook of Fuel Cell; John Wiley \& Sons: New York, 2003; Vol. 2.

29. Mukerjee, S.; McBreen, J. J. Electroanal. Chem. 1998, 448, 163.

30. Hammer, B.; Norskov, J. K.; Bruce, C. G.; Helmut, K. Adv. Catal.; Academic Press: 2000; Vol. 45.
31. Lopez, N.; Janssens, T. V. W.; Clausen, B. S.; Wu, Y.; Mavrikakis, M.; Bligaard, T.; Norskov, J. K. J. Catal. 2004, 223, 232.

32. Mayrhofer, K. J. J.; Blizanac, B. B.; Arenz, M.; Stamenkovic, V. R.; Ross, P. N.; Markovic, N. M. J. Phys. Chem. B 2005, 109, 14433.

33. Han, B. C.; Miranda, C. R.; Ceder, G. Phys. Rev. B 2008, 77, 075410.

34. Kim, B.-J.; Kwon, K.; Rhee, C. K.; Han, J.; Lim, T.-H. Electrochim. Acta 2008, 53, 7744.

35. Yoon, S.-H.; Lim, S.; Hong, S.-h.; Qiao, W.; Whitehurst, D. D.; Mochida, I.; An, B.; Yokogawa, K. Carbon 2005, 43, 1828.

36. Bock, C.; Paquet, C.; Couillard, M.; Botton, G. A.; Macdougall, B. R. J. Am. Chem. Soc. 2004, 126, 8028.

37. Kim, T.; Lim, S.; Kwon, K.; Hong, S.-H.; Qiao, W.; Rhee, C. K.; Yoon, S.-H.; Mochida, I. Langmuir 2006, 22, 9086.

38. Jung, C.; Kim, J.; Rhee, C. K. Langmuir 2007, 23, 9495.

39. Clavilier, J.; Feliu, J. M.; Aldaz, A. J. Electroanal. Chem. 1988, 243, 419.

40. Debies, T. P.; Rabalais, J. W. Chem.Phys. 1977, 20, 277.

41. Briggs, D.; Seah, M. P. Practicle Surface Analysis by Auger and $X$-ray Photoelectron Spectroscopy; John Willey \& Sons: New Tork, 1990; Vol. 1.

42. Cherstiouk, O. V.; Simonov, P. A.; Zaikovskii, V. I.; Savinova, E. R. J. Electroanal. Chem. 2003, 554-555, 241.

43. Friedrich, K. A.; Henglein, F.; Stimming, U.; Unkauf, W. Electrochim. Acta 2000, 45, 3283.

44. Yoo, H. D.; Jang, J. H.; Ka, B. H.; Rhee, C. K.; Oh, S. M. Langmuir 2009, 25, 11947.

45. Herrero, E.; Feliu, J. M.; Aldaz, A. J. Catal. 1995, 152, 264. 